\title{
Study on Fish Migration through a Stone-Embedded Fish Passage Based on Preference
}

\author{
Rina FEBRINA ${ }^{1)}$, , Masahiko SEKINE ${ }^{2)}$, Hiroshi KANEMOTO ${ }^{2)}$, Koichi YAMAMOTO ${ }^{2)}$, \\ Ariyo KANNO ${ }^{2)}$, Takaya HIGUCHI ${ }^{2)}$, Tsuyoshi IMAI ${ }^{3)}$ \\ 1) Department of Civil Engineering, Faculty of Engineering, Malahayati University, Jl.Pramuka \\ No. 27 Kemiling, Bandar Lampung 35153, Indonesia \\ 2) Division of Civil and Environmental Engineering, Graduate School of Science and \\ Engineering, Yamaguchi University, 2-16-1 Tokiwadai, Ube, Yamaguchi 755-8611, Japan \\ 3) Division of Science and Engineering, Graduate School of Science and Engineering, \\ Yamaguchi University, 2-16-1 Tokiwadai, Ube, Yamaguchi 755-8611, Japan
}

\begin{abstract}
A stone-embedded fish passage (SEF) allows fish to pass a barrier by reducing the velocity in the slope. The efficiency of SEFs has however not been evaluated well and the design parameters are not clear. The efficiency of SEFs for fish therefore needs to be evaluated and analyzed. In this research, we attempted to develop a simple equation to estimate the passability of an SEF for Ayu (Plecoglossus altivelis), which is applicable in the SEF's designing stage. We reproduced the SEF conditions experimentally. The set-up consisted of a pool and a channel, and evaluated its passability based on physical conditions such as air bubbles, velocity, and depth. With the results, we developed a decision tree to explain the passability using design variables such as discharge, channel slope, and pool size and depth. Then, to estimate the whole SEF, we proposed an equation which calculated the average of the decision tree outputs throughout the SEF's whole ascending routes. Lastly, we verified the equation through field experiments. The equation showed good agreement with the observed fish ascent success rate. This technique could therefore be used to evaluate a SEF in its designing stage.
\end{abstract}

Keywords: decision tree, preference of Ayu, stones-embedded fish passage

\section{INTRODUCTION}

Upstream or downstream fish migration takes place for purposes such as food and spawning. Barriers across rivers often have negative impacts on natural fish populations and, along with other factors, may contribute to the diminished abundance, disappearance, or even extinction of species. Fish passages are installed to minimize the severe impact on the river ecosystem. The effectiveness of a fish passage is closely linked to the water velocities and flow patterns and its design should take into account the behavior of the target species.

In Japan, pool and weir fish passages commonly provided upstream routes for Ayu (Plecoglossus altivelis), which is an amphidromous species and is one of the most important commercial fish in Japan (Ishida, 1976). However, these traditional fish passages have sometimes been degraded because of river bed degradation or other problems and many of them require restoration. Recently, the stone-embedded fish passage (SEF) is gaining popularity in some areas of Japan as an inexpensive small-scale river restoration method. The Fushino River SEF is such a passage, intended to improve or substitute existing pool and weir fish passages. Although the Fushino River SEF has been widely introduced through a book (Project Team "Mizube no Kowaza", 2007) and has been highly appreciated, the efficiency of the SEF has not been

Address correspondence to Rina Febrina, Department of Science and Engineering, Graduate School of Science and Engineering, Yamaguchi University, Email: r007wc@yamaguchi-u.ac.jp

Received May 23, 2014, Accepted September 19, 2014. 
evaluated well and its design parameters are not yet clear enough. We conducted a preliminary survey on the Fushino River SEF in 2011. Unlike the expectation that stones would be used for roughness, the Fushino River SEF was a network of small pools and channels under its operating discharge (Fig. 1). Also, observation during the survey showed that air bubbles, high velocity, and low channel and pool depths were major obstacles for fish ascendance. Existing SEF research (Miyazono and Tomatsu, 2003; Miyazono et. al., 2005; Fujihara and Chhatkuli, 2006) modeled them as stones on a flat bed and did not take air bubbles into account. A small amount of air bubbles would increase the dissolved oxygen and create favorable conditions for fish. However, a large amount of air bubbles would reduce the water density and inhibit fish movement. The purpose of this research was to build a simple model, applicable to the SEF design stage, to estimate the passability of the SEF for Ayu, using preference information on velocity, depth, and air bubbles. We then verified the model through field experiments in the Fushino River SEF.

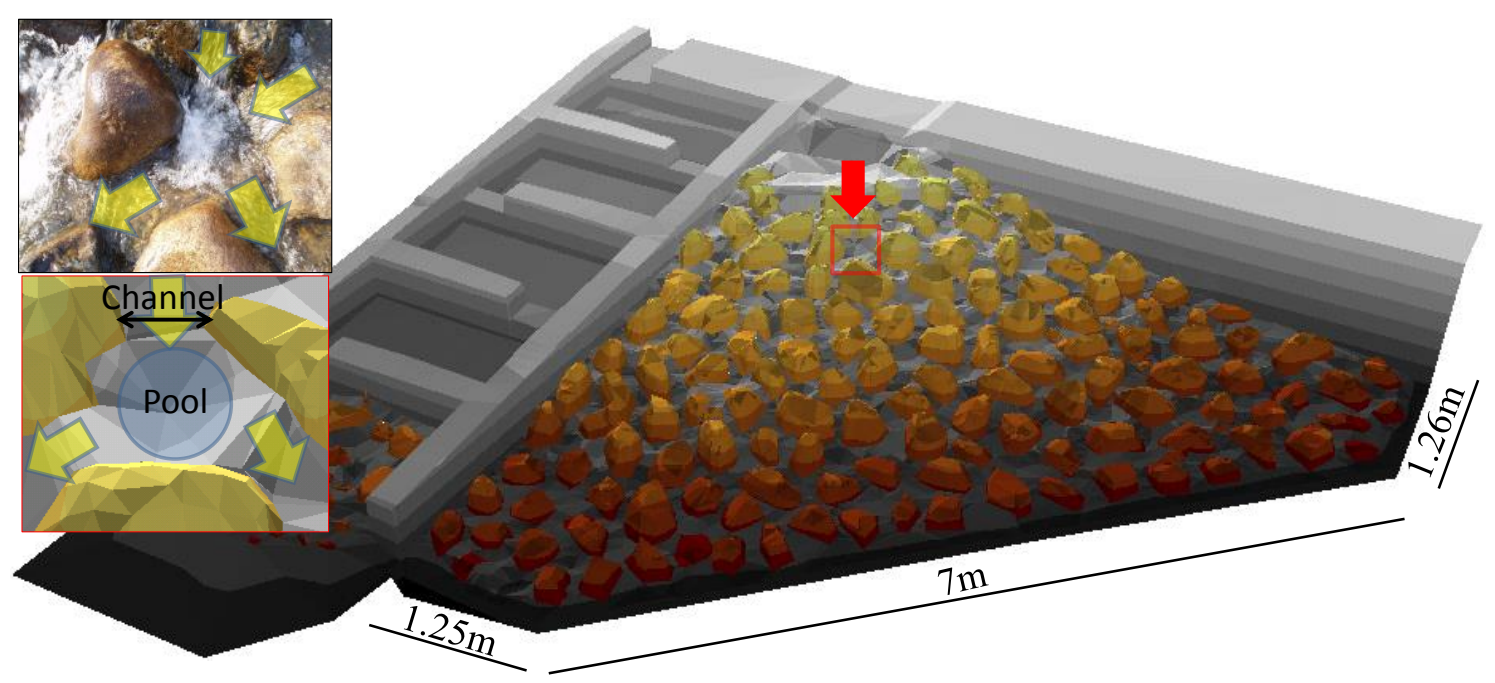

Fig. 1 - Network of small pools and channels at the Fushino River SEF. 


\section{MATERIALS AND METHODS}

\section{Laboratory experiment}

The experimental setup consisted of a pool and a channel (Fig. 2a). A schematic overview of the experimental setup is shown in Fig. $2 \mathrm{~b}$. It was made of transparent acrylic. In this experiment, the depth of the pool (DoP) was changed by replacing bottom plate spacers, the length of the channel (LoC) by replacing the channel parts, and the slope of the channel (SoC) by lifting the upper tank. Width of the channel (WoC) was fixed at $10 \mathrm{~cm}$. The slope of the flood gate $(\mathrm{SoG})$ was adjusted to make a smooth water surface level transition in the channel and pool. The experimental flow rate $(\mathrm{Q})$ was measured at the flood gate. Depth of the channel (DoC) was measured at the center of the channel. Velocity of the channel $(\mathrm{VoC})$ was calculated as $\mathrm{VoC}=\mathrm{Q} /$ $(\mathrm{DoC} \times \mathrm{WoC})$.

The conditions of the Fushino River SEF were represented in the laboratory experiments. Table 1 lists the observed characteristics in the SEF and the experimental conditions. Velocity and air bubbles were measured in the pool at the points shown in Fig. 3. Velocity of pool (VoP) was measured using two propeller type velocity meters (VR-201 or SV-3, KENEK, Tokyo, Japan), depending on the depth. The bubble condition index $(\mathrm{BCI})$ was observed where $\mathrm{BCI}=0$ : no air bubble; 0.1: air bubbles appeared on the surface; 0.5: air bubbles reached the middle of the pool; and 1: air bubbles reached the bottom of pool.

(a)

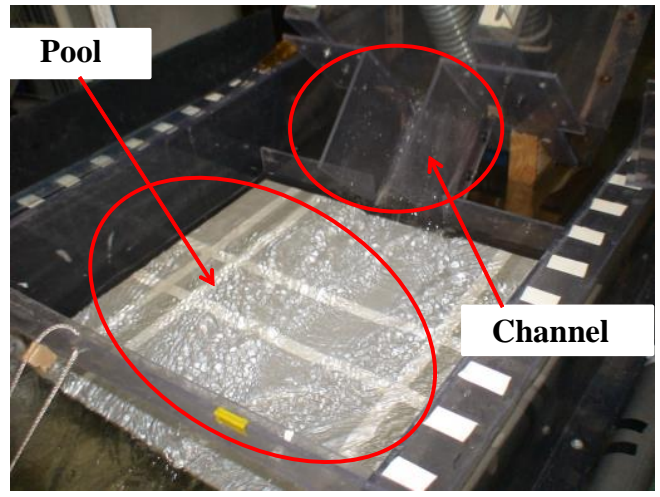

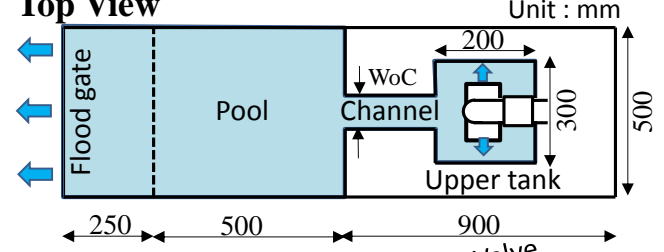

Side view

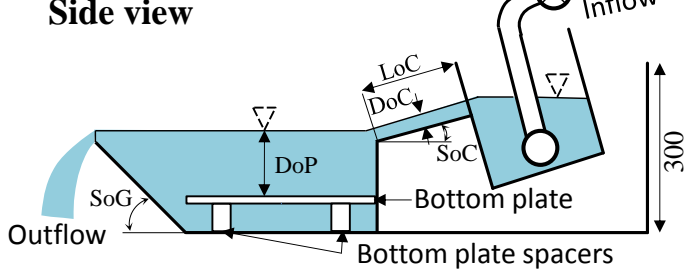

Fig. 2 - Experimental setup, with (a) the pool and channel, and (b) a schematic top and side view of the setup. 
Table 1 - Pool and channel parameters in the Fushino River SEF and the laboratory experiments.

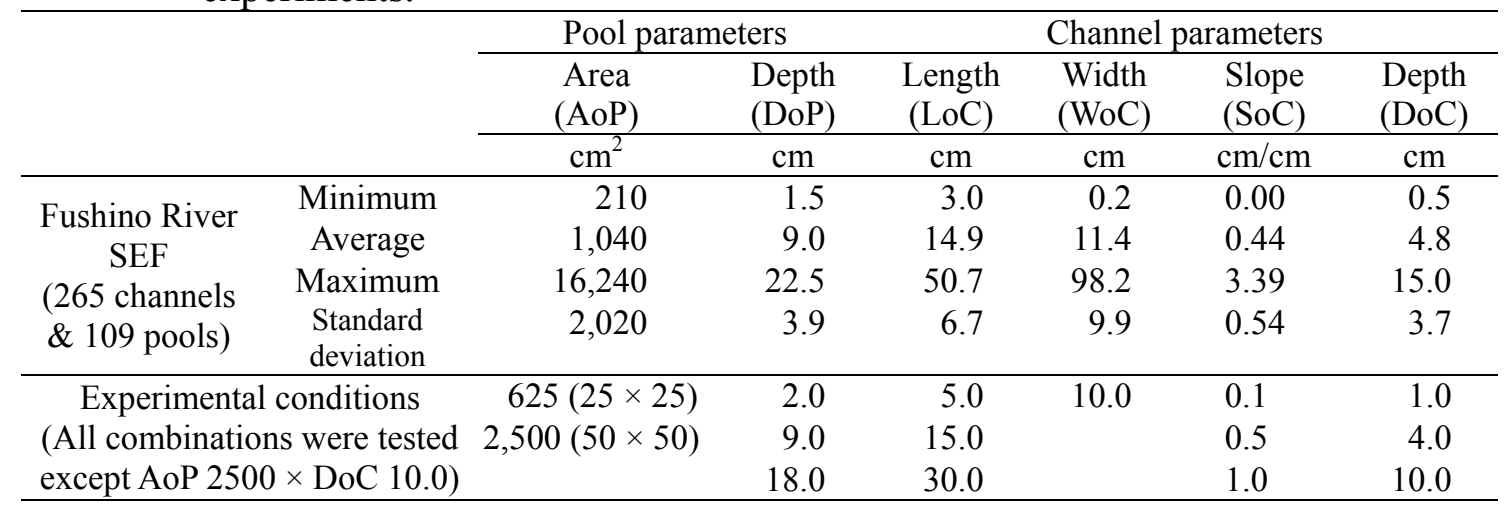

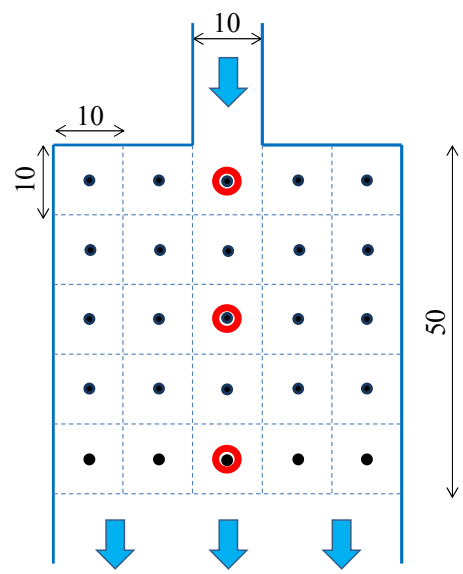

(a)
- Velocity measurement

- Air bubble measurement

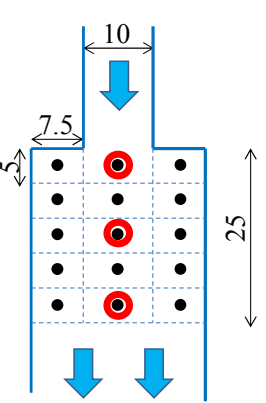

(b)

Fig. 3 - Measuring points for (a) the $50 \times 50 \mathrm{~cm}$ pool and (b) the $25 \times 25 \mathrm{~cm}$ pool.

\section{Estimation of passability in laboratory experiments}

We defined a set of rules to estimate the passability in the laboratory experiment based on preference information on velocity, air bubbles, depth, and space. We assumed that Ayu's body length (BL) was $6 \mathrm{~cm}$ (BL6) and the body height (BH) was $1.3 \mathrm{~cm}$, because this is a common size when they start upstream migration and because Ayu of this size was used in some of our previous research, which we refer to below.

Velocity

Nakamura (1995) stated that fish can swim at burst speed just for a few seconds, while they can swim for hours at cruising speed. Ayu's burst speed is $12-18 \mathrm{BL} / \mathrm{s}$ and their cruising speed is $4-7 \mathrm{BL} / \mathrm{s}$. Sekine et al. (2009) used a preference model in which Ayu could not swim more than $4 \mathrm{~s}$ at burst speed. With this information we defined two rules: time of ascending (ToA) $<4 \mathrm{~s}$ and $\mathrm{VoP}<$ cruising speed. Time of ascending was calculated using ToA $=$ LoC / (burst speed $-\mathrm{VoC}$ ). Burst speed and cruising speed were calculated by $15 \mathrm{BL} / \mathrm{s}$ and $5.5 \mathrm{BL} / \mathrm{s}$ respectively. 


\section{Air bubbles}

Noguchi et al. (2007) experimentally estimated a preference of Ayu for air bubbles using a scale of 0 (no preference) to 1 (maximum preference). In the research, Ayu showed the highest preference of 1 at $0 \%(\mathrm{v} / \mathrm{v})$ air and showed a slightly lower preference of 0.75 at $5 \%(\mathrm{v} / \mathrm{v})$ air. After that, preference quickly decreased down to 0.13 at $10 \%(\mathrm{v} / \mathrm{v})$ air and became almost zero for $20 \%(\mathrm{v} / \mathrm{v})$ air. Water with $5 \%(\mathrm{v} / \mathrm{v})$ air bubbles was acceptable for fish to stay and move. We also learned through our field observations that bubbles tended to stay in the upper layer of the water and that fish could stay in the bottom layer when it had no bubble area. With this information we defined a rule: $\mathrm{BCI} \leq 0.1$ when $\mathrm{DoP}=2 \mathrm{~cm}$ and $\mathrm{BCI} \leq 0.5$ when $\mathrm{DoP}=9,18 \mathrm{~cm}$.

\section{Depth}

Nakamura (1995) stated that the minimum water depth for swimming was two times $\mathrm{BH}$. However we frequently observed Ayu swimming through shallow water with their back emerged in the air. With this information we define a rule: $\mathrm{DoP} \geq \mathrm{BH}$.

\section{Space}

Nakamura (1995) stated that minimum rest place size was $2-4$ BL long and $1 / 2$ BL wide. We determined the passability of a channel and each cell (a rectangular area with one velocity measuring point in a pool) based on the rules described above. However, the cell length of the $25 \times 25 \mathrm{~cm}$ pool was $5 \mathrm{~cm}$ along the flow, which was smaller than Ayu's BL of $6 \mathrm{~cm}$. To determine the passability of a pool, we defined a rule: at least two connected passable cells were necessary for the $25 \times 25 \mathrm{~cm}$ pool and one passable cell was necessary for the $50 \times 50 \mathrm{~cm}$ pool.

With the rules above, we estimated the passability (IP: impassable, P: passable) for each experimental condition.

\section{Decision tree on passability of a channel and pool pair}

We employed the decision tree (Hullet, 2006) as a simplified method to estimate the passability of a channel and pool pair in the SEF designing stage. The explanatory variables were $\mathrm{Q}, \mathrm{SoC}, \mathrm{LoC}, \mathrm{DoP}$ and $\mathrm{WoP}$, all of which could be determined in the designing stage. Using a set of these explanatory variables and the passability as a dependent variable obtained through laboratory experiments, we built a decision tree using the statistical package $\mathrm{R}$.

\section{Field experiments for decision tree verification}

To verify the model, we applied the decision tree to the Fushino River SEF. We used three experimental conditions: experiment 1 used the whole SEF area; experiment 2 used the SEF's central zone, which represented the area with few air bubbles and low flow rate; and experiment 3 used the SEF's right bank, which represented the area with dense air bubbles and high flow rate. We released 100 (experiments 1 and 3), or 50 (experiment 2) Ayu downstream of the fish passage entrance and video recorded the number of Ayu that successfully passed through the SEF. Body length of the released Ayu was $7 \pm 1 \mathrm{~cm}$, which was slightly larger than the BL of $6 \mathrm{~cm}$ that we assumed in our passability estimation of the laboratory experiments. We also conducted an environmental condition survey on VoP and VoC using KENEK VR-201, BCI of pools by visual observation, and DoP and DoC using ruler. 


\section{RESULTS AND DISCUSSION}

Figure 4 shows the results of the passability estimations of the laboratory experiments. The most significant parameter was DoC, which was strongly related with Q. When DoC became deeper, the passability was reduced. Larger pool size positively affected the passability, because it increased the number of passable cells. Longer LoC and steeper slope negatively affected the passability.

Figure 5 shows the decision tree on the passability of a channel and pool pair. The decision tree also showed that $\mathrm{Q}$ was the most significant variable and that WoP, DoP, and SoC followed. Please note that the values in Fig. 5 strongly depended on the experimental conditions. For example, the WoP value of 37.5 for the second branch just distinguished $25 \mathrm{~cm}$ from $50 \mathrm{~cm}$ WoP. There was no difference when we estimated the results of the laboratory experiment, even when this value was 25.1 or $49.9 \mathrm{~cm}$. Because of this, we only showed the framework of the SEF estimation model here. To increase the applicability of the decision tree to other SEFs, more laboratory experiments with different condition would be required.

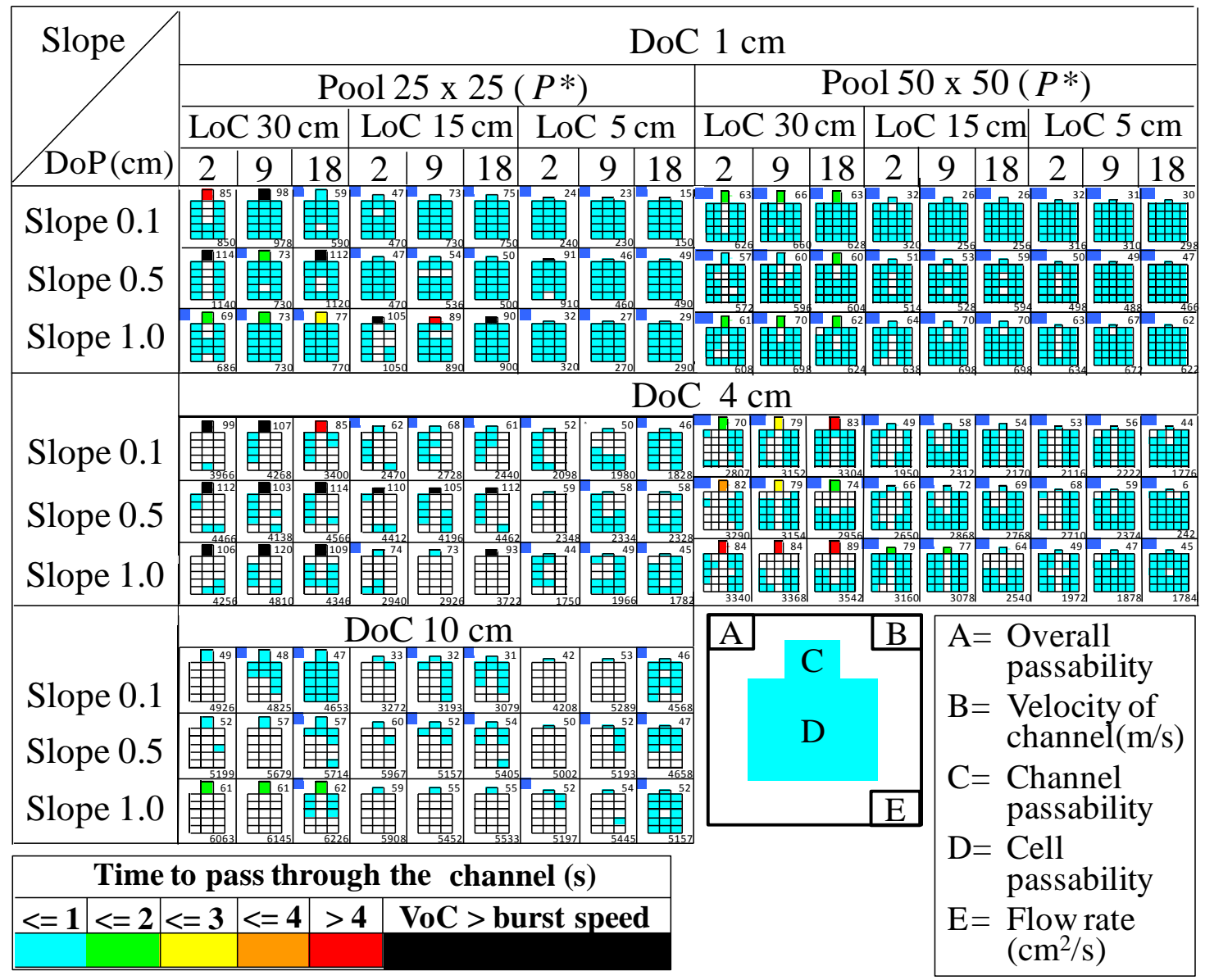

Note: The estimated passability in the pool (light blue cell = Ayu can rest in the cell, white cell = Ayu cannot rest in the cell); the estimated passability of channel (red and black channel = Ayu cannot pass through the channel, other colors = Ayu can pass through); total passability of the pool and channel (dark blue $=$ good, white $=$ not good).

Fig. 4 - Passability estimation of the laboratory experiments. 


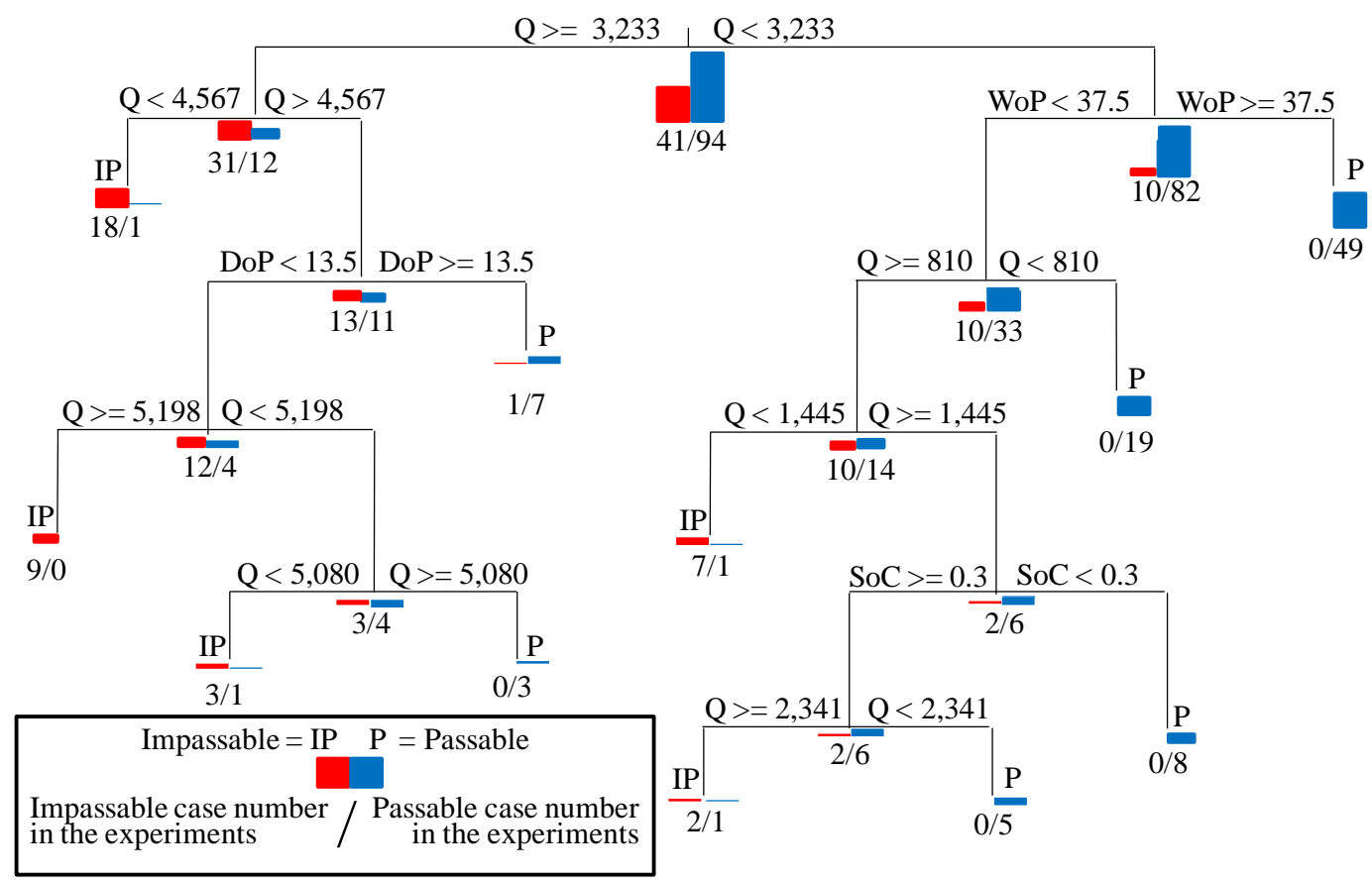

Fig. 5 - Decision tree on overall passability of a channel and pool pair.

Figure 6 shows the set-up of the field experiments. The experiments were conducted on the 12th (experiment 1), 14th (experiment 2), and 15th (experiment 3) of May and the 8th of June (environmental condition), 2013. The flow rates entering the SEF were $0.050 \mathrm{~m}^{3} / \mathrm{s}, 0.064 \mathrm{~m}^{3} / \mathrm{s}, 0.058 \mathrm{~m}^{3} / \mathrm{s}$, and $0.058 \mathrm{~m}^{3} / \mathrm{s}$ on these dates, respectively. Water temperature was approximately $17^{\circ} \mathrm{C}$ for all experiments. During the environmental condition survey, parameter values were measured at about one fourth of all pools and channels to cover as wide range of parameter values as possible. For un-measured pools and channels, parameter values were estimated using a result of another survey, which had been conducted for all pools and channels on 28th January 2011 under a flow rate of $0.083 \mathrm{~m}^{3} / \mathrm{s}$. The 2013 values of the target pool/channel were calculated based on the average ratio of the 2011 and 2013 values of the similar pools/channels which had both 2011 and 2013 values. Figure 7 shows the environmental conditions at the SEF. Table 2 shows the number of successfully ascended Ayu. Interestingly, even if the fish ascending routes in experiment 1 included all ascending routes in experiment 2 , the ascent success rate of experiment 1 within 30 minutes was much smaller than that of experiment 2. This might be because the fish could not estimate the whole route's passability and had a chance to enter an impassable route even when a passable route existed. 


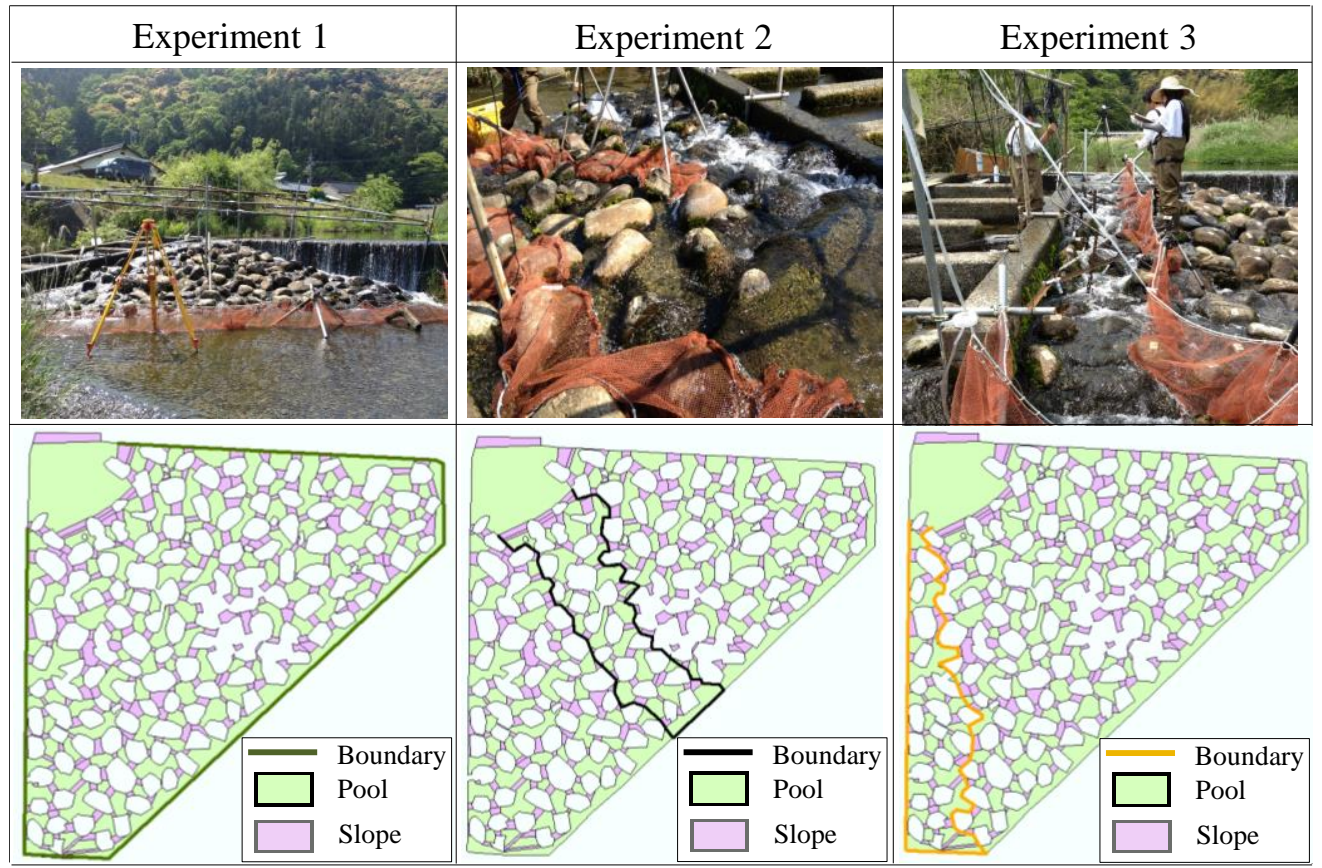

Fig. 6 - Experimental area.

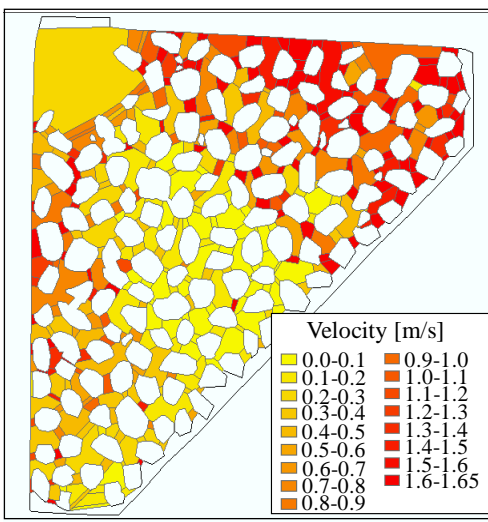

(a)

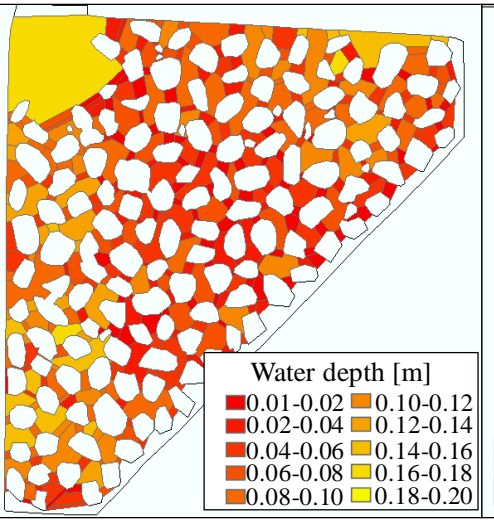

(b)

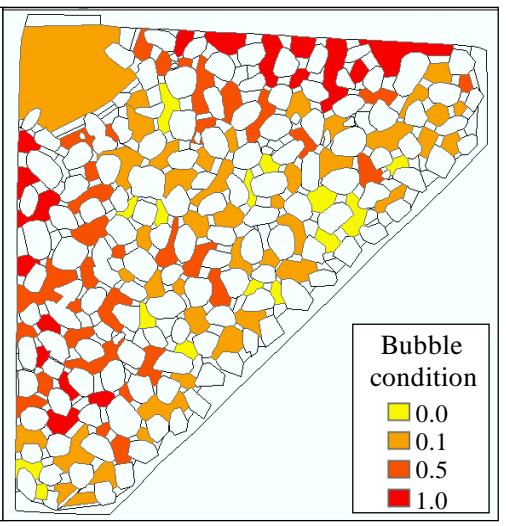

(c)

Fig. 7 - Environmental conditions at the Fushino River SEF, with (a) velocity (b) water depth, and (c) bubble condition.

Table 2 - Number of successfully ascended Ayu.

\begin{tabular}{lccccc}
\hline & $\begin{array}{c}\text { Investigation } \\
\text { time [h] }\end{array}$ & $\begin{array}{c}\text { Number } \\
\text { of } \\
\text { released } \\
\text { Ayu }\end{array}$ & $\begin{array}{c}\text { Number of } \\
\text { ascended Ayu }\end{array}$ & $\begin{array}{c}\text { Number of } \\
\text { ascended Ayu } \\
\text { within 30 minutes }\end{array}$ & $\begin{array}{c}\text { Ascent success rate } \\
\text { within 30 minutes [\%] }\end{array}$ \\
\hline Experiment 1 & 20.0 & 100 & 71 & 4 & 4 \\
Experiment 2 & 0.5 & 50 & 27 & 27 & 54 \\
Experiment 3 & 0.5 & 100 & 17 & 17 & 17 \\
\hline
\end{tabular}


We evaluated the Fushino River SEF using the decision tree and based on the environmental conditions (Fig. 8). To estimate $Q$ for each channel, the flow rate entering the upper pool was distributed to each downstream channel based on their discharge section area. Then, the estimated results of the decision tree $(=E p$, which is 0 when impassable or 1 when passable) were given to each channel, not to each channel and pool pair. This was because some pools were paired with multiple channels and such pairs, sharing the same pool, sometimes showed different results. In Fig. 8 all ascending routes had more than one impassable channel and pool pair. This was even true for experiment 2, in which more than $50 \%$ fish had ascended. This might be because of the BL difference between the field observation $(7 \mathrm{~cm})$ and the decision tree $(6 \mathrm{~cm})$.

Furthermore, to estimate the whole SEF's performance, we determined the following equation:

$$
E_{w}=\frac{1}{N_{r}} \sum_{1}^{N_{r}}\left(\frac{1}{N_{c}} \sum_{1}^{N_{c}} E_{p}\right)
$$

where $E_{w}$ is the estimation of the whole SEF, $N_{r}$ is the total number of routes to ascend the SEF, $N_{c}$ : number of channels on a route, and $E_{p}$ is the estimation for a channel-pool pair using the decision tree. We counted up all possible routes, $N_{r}$, for Ayu to ascend the SEF. The total number of routes to ascend the SEF was 171,071, 192, and 1,584 for experiments 1,2 , and 3 , respectively.

Figure 9 shows the relationship between the estimation of the whole SEF's performance, $E_{w}$, and the ascent success rate within 30 minutes, which was positive. This was also true for different time spans of 15 to $30 \mathrm{~min}$. This indicates that our estimation model successfully explained the efficiency of the Fushino River SEF. 


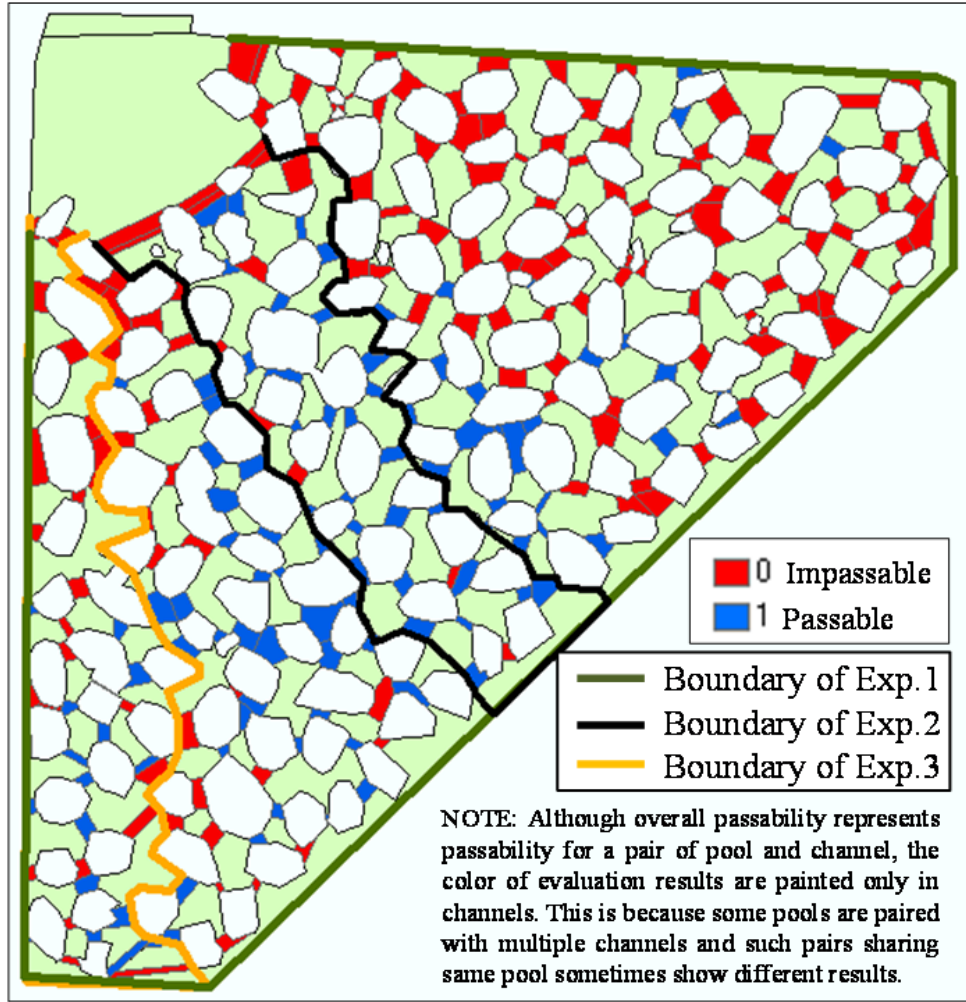

Fig. 8 - Overall passability based on the decision tree for BL6 Ayu.

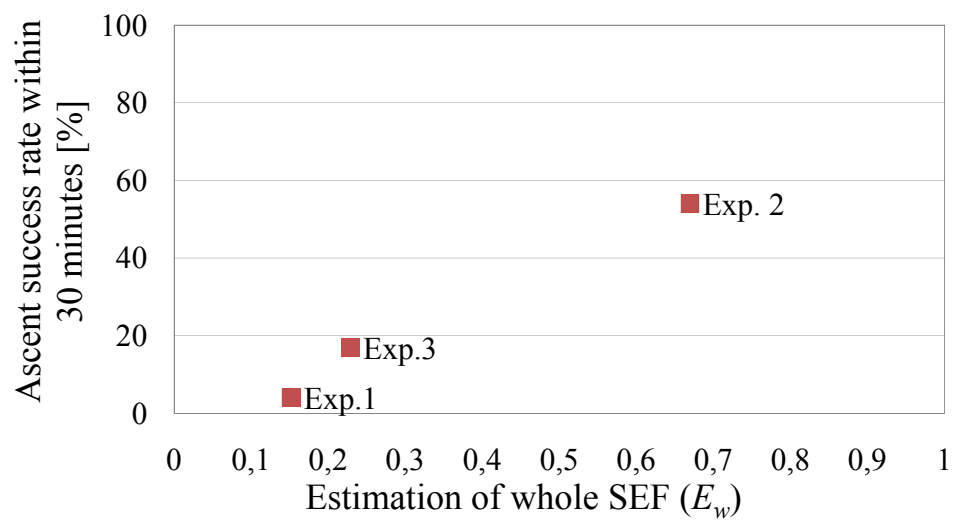

Fig. 9 - Relationship between the estimation of whole SEF and the ascent success rate within 30 minutes.

\section{CONCLUSIONS}

We developed a decision tree to estimate the passability of a channel and pool pair in an SEF, based on a laboratory experiment. Then, we proposed an equation to estimate the whole SEF, combining the estimation results of the decision tree. The estimation equation showed a good relationship with the fish ascent success rate of the field 
experiments. With this research we provided a framework for SEF estimation. To increase the applicability of this method to other SEFs, experiments with different conditions would be required.

\section{REFERENCES}

Fujihara M. and Chhatkuli S. (2006) Numerical flow modeling over semi-spherical obstructions in a series - Toward a numerical modeling of nature-like fishways embedded with stones. Trans. Jpn. Soc. Irri. Drain. Reclam. Eng., 74(6), 151-160.

Hullet D. T. (2006) Use decision tree to make important project position. PM Network.

Ishida R. (1976) An investigation of spawning behavior of the Ayu. Anima., 43, 12-20. (in Japanese)

Miyazono M. and Tomatsu O. (2003) Arrangement of protruding boulders in a slanted fishway. J. Jpn. Soc. Eros. Control Eng., 56(1), 3-12. (in Japanese)

Miyazono M., Takauzi T. and Tomatsu O. (2005) Hydraulic characteristics and natatorial action of fish around boulders. J. Jpn. Soc. Eros. Control Eng., 57(5), 15-24. (in Japanese)

Nakamura S. (1995) Gyodou no Hanashi (Story of Fishway), Sankai-do, Tokyo, Japan, pp.30-80. (in Japanese)

Noguchi H., Sekine M., Watanabe M. and Ukita M. (2007) Study on the quantification of environmental preference of ayu by indoor experiment focusing on the river local environment. Environ. Eng. Res., 44, 75-81. (in Japanese)

Project Team "Mizube no Kowaza" (2007) Mizube no Kowaza (small restoration works in the waterside). Civil and Architecture Section of Yamaguchi Prefecture, Japan. (in Japanese)

Sekine M., Noguchi H., Imai T. and Higuchi T. (2009) Modelling fish preference for water gaps to determine migration path. Proc. 7th International symposium on ecohydraulics, 12-16 Jan., Concepcion, Chile. (CD-ROM) 